\title{
Hydrogenation of $o$-Cresol on Platinum Catalyst: Catalytic Experiments and First-Principles Calculations
}

Yaping Li ${ }^{\mathrm{a}}$, Zhimin Liu ${ }^{\mathrm{b}}$, Wenhua Xue ${ }^{\mathrm{a}}$, Steven P. Crossley ${ }^{\mathrm{b}}$, Friederike C. Jentoft ${ }^{\mathrm{b}, 1}$, and Sanwu Wang $^{\mathrm{a}, \dagger}$

${ }^{a}$ Department of Physics and Engineering Physics, The University of Tulsa, Tulsa, Oklahoma 74104, USA.

b School of Chemical, Biological and Materials Engineering, University of Oklahoma, Norman, Oklahoma 73019, USA

\begin{abstract}
Catalytic experiments were performed for the hydrogenation of $o$-cresol in $n$-dodecane over a platinum catalyst. Batch reactions analyzed with an in-situ ATR IR probe suggest that the hydrogenation results in the formation of the final product, 2-methyl-cyclohexanol, with 2-methyl-cyclohexanone as the intermediate product. Ab initio density-functional theory was employed to investigate the atomic-scale mechanism of $o$-cresol hydrogenation on the $\operatorname{Pt}(111)$ surface. The formation of 2-methyl-cyclohexanone was found to involve two steps. The first step is a hydrogen abstraction, that is, the $\mathrm{H}$ atom in the hydroxyl group migrates to the $\mathrm{Pt}$ surface. The second step is hydrogenation, that is, the pre-existing $\mathrm{H}$ atoms on $\mathrm{Pt}$ react with the carbon atoms in the aromatic ring. On the other hand, 2-methyl-cyclohexanonol may be produced through two paths, with activation energies slightly greater than that for the formation of 2methyl-cyclohexanone. One path involves direct hydrogenation of the aromatic ring. Another path involves three steps, with the partial hydrogenation of the ring as the first step, hydrogen abstraction of the $-\mathrm{OH}$ group as the second, and hydrogenation of remaining $\mathrm{C}$ atoms and the $\mathrm{O}$ atom the last.
\end{abstract}


Keywords: Hydrogenation, cresol, platinum catalyst, ab initio calculations, activation energies

${ }^{1}$ Present address: Department of Chemical Engineering, University of Massachusetts, Amherst, Massachusetts 01003, USA.

${ }^{\dagger}$ Author to whom correspondence should be addressed. Tel.: +1 918631 3022. Electronic mail: sanwu-wang@utulsa.edu (S. Wang).

\section{Introduction}

Biofuels derived from lignocellulosic biomass have received significant attention lately due to environmental concerns and increasing needs of energy supply [1-7]. Lignin-derived phenolics such as phenols, cresols and guaiacols are important components of crude bio-oil [8,9], but require upgrading prior to use [10]. Extensive research has been conducted for the conversion of phenolics to increase the stability of bio-oil and produce transportation fuels. The strong phenolic $\mathrm{OH}$ bond makes phenols and cresols, perhaps the most challenging biomass derived monomers to be deoxygenated. This has led to significant research efforts focused on the upgrading of phenolic compounds for improving the properties of bio-oils [11-17].

Cresol is a phenolic compound that has three isomers: ortho-cresol (o-cresol), meta-cresol ( $m$-cresol), and para-cresol ( $p$-cresol). Hydrogenation and hydrodeoxygenation of these three cresols were experimentally studied with various catalysts [18-25]. As early as 1967, it was demonstrated that hydrogenation of cresols with a rhodium catalyst generated methylcyclohexanols at the mild reaction temperature of $353 \mathrm{~K}$, but $o$-cresol was found to yield a significant amount of the ketone intermediate, 2-methyl-cyclohexanone [18]. Hichri et al. studied hydrogenation of $o$-cresol on $\mathrm{Ni} / \mathrm{SiO}_{2}$ in isopropanol at the reaction temperatures of $393-413 \mathrm{~K}$. 
They found that 2-methyl-cyclohexanol was the final product, but little 2-methyl-cyclohexanone was reported during the catalytic reaction [19]. Also using a $\mathrm{Ni} / \mathrm{SiO}_{2}$ catalyst, Shin and Keane [20] found that, at $473 \mathrm{~K}$, cresol conversion produced both methyl-cyclohexanols and methylcyclohexanones with the latter as the intermediate products. Toluene was reported at more severe conditions of $573 \mathrm{~K}$ along with methyl-cyclohexanols and methyl-cyclohexanones. Other investigations have reported similar behavior [21-23]. For example, hydrodeoxygenation of $o-$, $m$-, and $p$-cresols on sulfided $\mathrm{CoO}-\mathrm{MoO} / \gamma-\mathrm{Al}_{2} \mathrm{O}_{3}$ (in hexadecane) at $498-673 \mathrm{~K}$ resulted in toluene and methyl-cyclohexane as the major products [21]. More recently, Nie et al. reported that the dominant product of selective conversion of $m$-cresol over bimetallic Ni-Fe catalysts at $573 \mathrm{~K}$ was toluene [23]. Similar observations were made by Zanuttini et al. for hydrodeoxygenation of $m$-cresol at $573 \mathrm{~K}$ with Pt supported on acidic supports [24]. On the other hand, at a relatively lower temperature $(453 \mathrm{~K})$, both hydrogenation and hydrodeoxygenation of cresols were observed (over Pt/Beta zeolite in isooctane) [25].

In the last several years, a number of groups have reported their theoretical investigations for the catalytic conversions of phenol, guaiacol, and $m$-cresol on metal catalysts $[11-15,23,26,27]$. In particular, Nie et al. reported their calculations for determining the structure of $m$-cresol on several $\mathrm{Ni}, \mathrm{Fe}$, and $\mathrm{NiFe}$ surfaces [23] while Tan et al. reported their theoretical studies for the hydrodeoxygenation of $m$-cresol over platinum and ruthenium catalysts [27]. The atomic-scale mechanism of hydrogenation of $o$-cresol and $p$-cresol was not investigated, however. In this paper, we report results of a combination of an experimental work and ab initio calculations based on density-functional theory (DFT) for catalytic hydrogenation of $o$-cresol with platinum as the catalyst. In particular, we provide detailed data for energetics and reaction pathways, which are used to elucidate the reaction mechanisms at the atomic-scale. 


\section{Experimental and Computational Methods}

\subsection{Materials}

$o$-cresol (99\%), 2-methyl-cyclohexanone $(\geq 99.5 \%)$, and $n$-dodecane $(\geq 99 \%)$ were obtained from Sigma Aldrich Company. All chemicals were used without further purification. Platinum on carbon (5 wt. \% loading, 205931-Aldrich) was used as catalyst.

\subsection{Catalytic tests}

The catalytic experiments were conducted in batch mode in a custom design Parr reactor of $300 \mathrm{ml}$ volume. Quantitative analysis of the composition of the reaction mixture was performed by attenuated total reflection (ATR) IR spectroscopy. A Mettler-Toledo Sentinel ${ }^{\mathrm{TM}}$ DiComp $^{\mathrm{TM}}$ High Pressure ATR-IR probe was connected to a ReactIR ${ }^{\mathrm{TM}} \mathrm{iC} 10$ module with a K4 conduit. The ATR-IR probe was integrated into the reactor side wall to avoid settling of catalyst particles into the cavity of the probe, right above the crystal. The lid of the reactor was equipped with a pressure transducer. In typical experiments, $120 \mathrm{~mL}$ of solvent and $25 \mathrm{mg}$ of catalyst were charged into the reactor. The reactor was then purged five times with $\mathrm{H}_{2}$. Subsequently, the reactor was pressurized with 200 psi $\mathrm{H}_{2}$ and heated from room temperature to the reaction temperature of $408 \mathrm{~K}$ and kept at this temperature for $10 \mathrm{~min}$ before the IR background was collected. The reaction was started by injection of the reactant (o-cresol). IR spectra were collected every $30 \mathrm{~s}$ in the first 2 hours and every $1 \mathrm{~min}$ in the following several hours.

\subsection{Ab initio calculations}

$A b$ initio calculations were based on density functional theory, the projector augmented wave (PAW) method, and plane-wave basis sets [28-37]. All the calculations were performed with the use of Vienna $a b$ initio simulation package (the VASP code) [28-30]. The functionals within 
generalized gradient approximations, developed by Perdew, Burke, and Ernzerhof (PBE), were used to describe the exchange and correlation effects [32]. The Pt(111) surface was represented by a repeated supercell that contains a slab of Pt atoms and a vacuum region of $18 \AA$ in height, as shown in Fig. 1. The slab consists of five metal layers with each layer containing 25 platinum atoms in the supercell (a $5 \times 5$ surface unit cell). The Pt atoms were initially located at their bulk positions with the bulk lattice constant determined by our calculations. In order to calculate the adsorption of a molecule, the molecule was initially placed on the top of the Pt slab (at various positions near the surface). Each configuration was then optimized via a conjugate-gradient technique using the total energy and the Hellmann-Feynman forces on the atoms [33]. For all the optimization calculations, the Pt atoms of the bottom two layers were fixed while the Pt atoms of the top three layers and all the atoms of the molecule were allowed to move until the forces on all the atoms that were allowed to relax were less than $0.05 \mathrm{eV} / \AA$. The van der Waals (vdW) correction proposed by Tkatchenko and Scheffler [38] was added to the conventional DFT for determining adsorption geometries and energies. Reaction pathways and the associated barriers were determined with the conventional DFT using the climbing image nudged elastic band method [39,40]. A plane-wave energy cutoff of $400 \mathrm{eV}$ and two special $\boldsymbol{k}$ points in the irreducible part of the two-dimensional Brillouin zone of the $5 \times 5$ surface cell were used for all the calculations.

\section{Results and Discussion}

The hydrogenation of $o$-cresol in the batch phase as monitored via in-situ ATR-IR spectra over $\mathrm{Pt} / \mathrm{C}$ in dodecane reveals 2-methyl-cyclohexanone as an intermediate product as shown in 


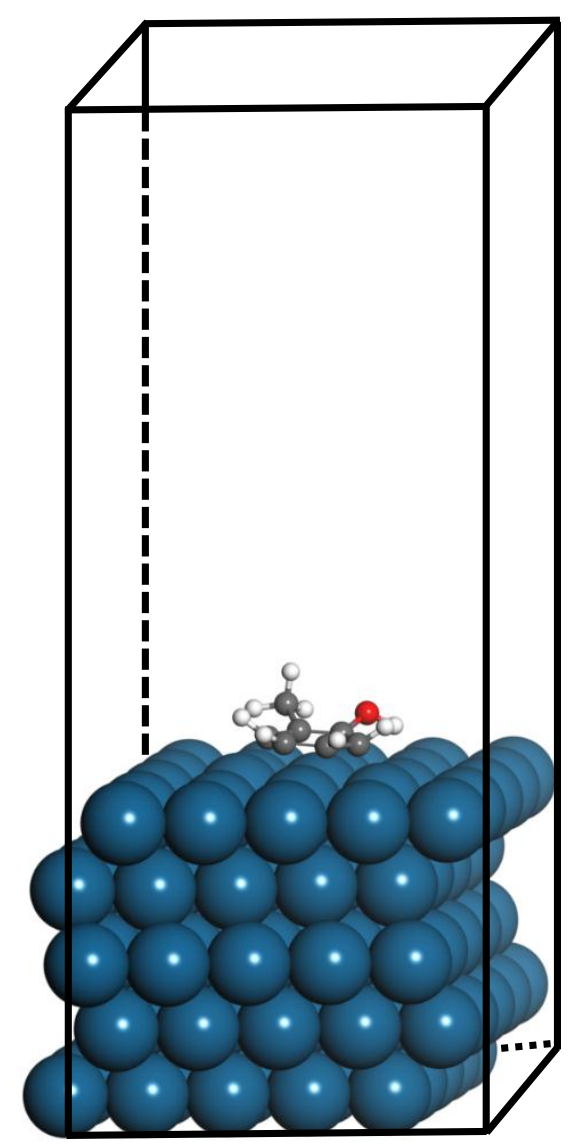

Figure 1. Schematics of the supercell model for adsorption of $o$-cresol on the $\operatorname{Pt}(111)$ surface.

Figure 2. The intermediate is indicated by the appearance of IR band at $1723 \mathrm{~cm}^{-1}$, which is assigned to the $\mathrm{C}=\mathrm{O}$ vibration of 2-methyl-cyclohexanone. This product is also confirmed by GC-MS analysis of the liquid mixture. In order to obtain the concentration profiles of $o$-cresol and its hydrogenation products, calibrations based on the Lambert-Beer Law were performed by ATR-IR with specific IR bands of $o$-cresol $\left(1253 \mathrm{~cm}^{-1}\right), 2$-methyl-cyclohexanone $\left(1723 \mathrm{~cm}^{-1}\right)$ and 2-methyl-cyclohexanol $\left(976 \mathrm{~cm}^{-1}\right)$. Based on the concentration profiles, the selectivity of 2-methyl-cyclohexanone and 2-methyl-cyclohexanol were very close in the first $30 \mathrm{~min}$. 

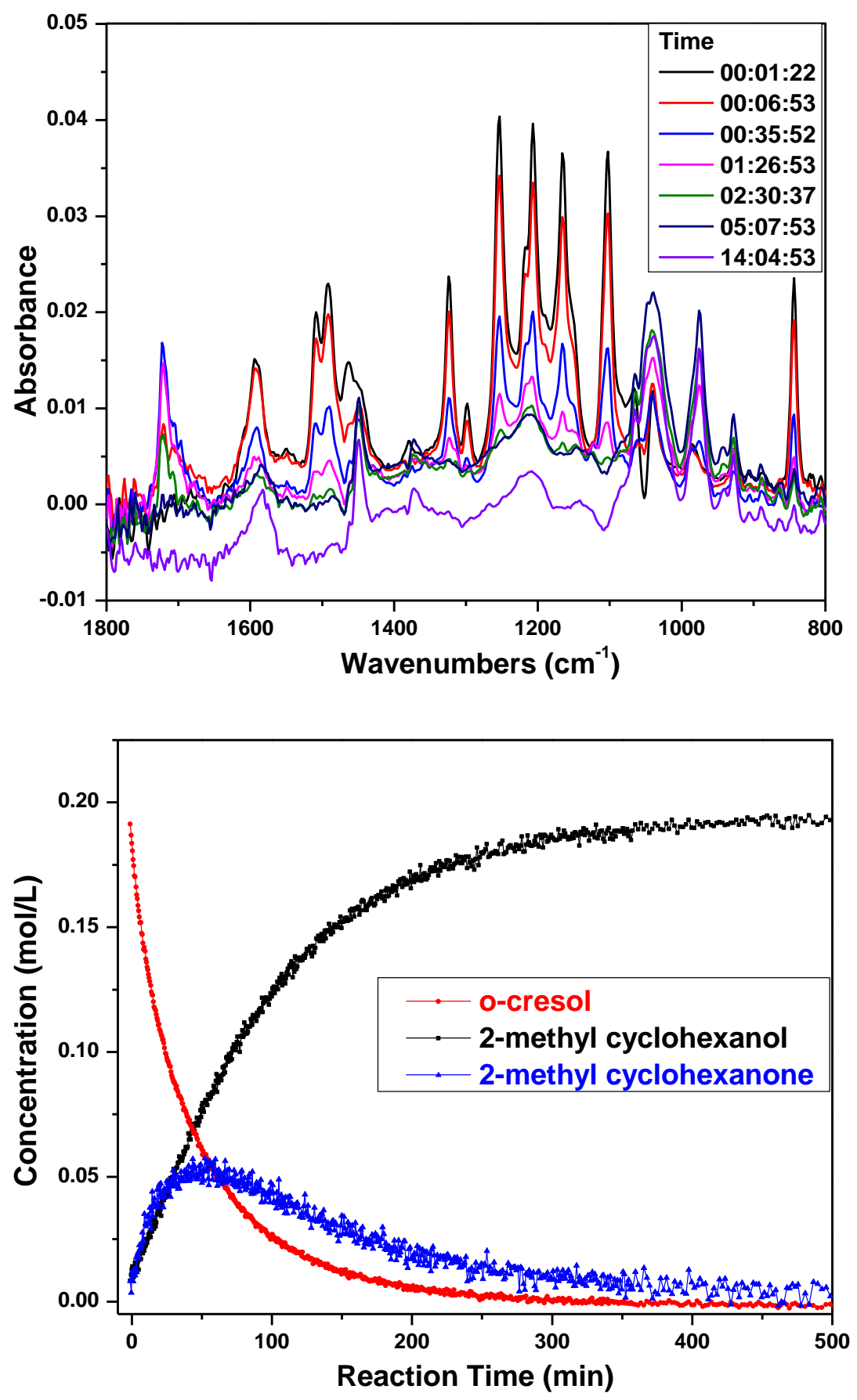

Figure 2. In-situ ATR-IR spectra (top) and concentration vs. time profiles from in-situ IR spectra (bottom) during the hydrogenation of $o$-cresol in n-dodecane on $\mathrm{Pt} / \mathrm{C}$. Reaction conditions: $n$ dodecane $(120 \mathrm{ml}), 5 \% \mathrm{Pt} / \mathrm{C}(25 \mathrm{mg}), 408 \mathrm{~K}$. 
2-methyl-cyclohexanone reached a maximum concentration after $50 \mathrm{~min}$ when the conversion of $o$-cresol was about ca. $65 \%$. After that the concentration of 2-methyl-cyclohexanone decreased slowly as it was subsequently converted to the 2-methyl-cyclohexanol. A plot of the 2-methylcyclohexanol selectivity as a function of conversion showed considerable scatter at low conversions. Extrapolation of the trend observed at higher conversions suggests a finite selectivity at zero conversion, implying that 2-methyl-cyclohexanol is also formed directly from cresol and not only as a secondary product.

$A b$ initio calculations were first performed for bulk platinum in order to determine its equilibrium lattice constant. Calculations for bulk Pt were conducted with 408 special $\boldsymbol{k}$ points and a cutoff energy of $400 \mathrm{eV}$. The total energy convergence with respect to the cutoff energy (300-450 eV) and the number of the $\boldsymbol{k}$ points (220-570) was within a few tenths of $1 \mathrm{meV}$ per atom. We obtained a lattice constant of $3.97 \AA$ (conventional DFT) or $3.93 \AA$ (DFT with the TS $\mathrm{vdW}$ corrections, hereafter DFT-vdW), in good agreement with the experimental value of $3.92 \AA$ [41]. Calculations were also performed for a single isolated $o$-cresol molecule, which was placed
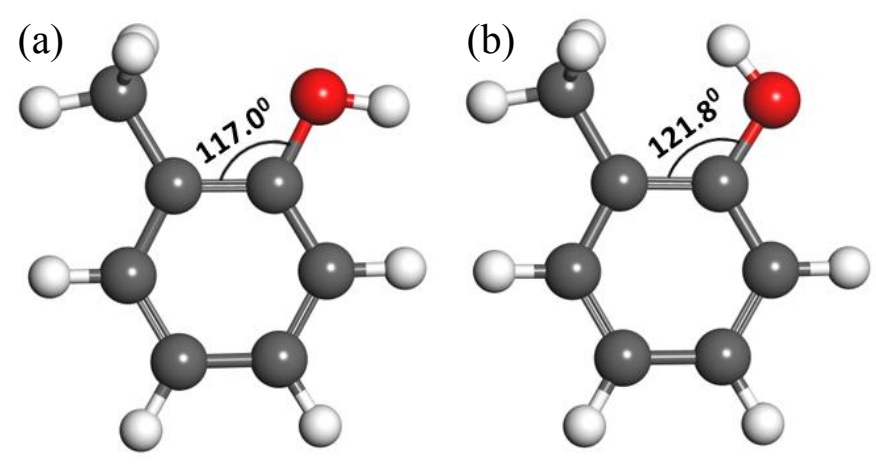

Figure 3. The two structure of the cresol determined with ab initio DFT calculations: (a) Transcresol, and (b) Cis-cresol. 
into a large supercell, with a cutoff energy of $400 \mathrm{eV}$ and 2 special $\boldsymbol{k}$ points. There are two possible structures for $o$-cresol, as shown in Fig. 3. One is the trans-structure in which the hydrogen atom of the hydroxyl group is away from the methyl group [Fig. 3(a)], and the other is the cis-structure in which the hydrogen is toward the methyl group [Fig. 3(b)]. Our calculations show that the structural parameters (bond lengths and bond angles) of both structures are almost the same except for the angles between the $\mathrm{O}-\mathrm{C}$ bond and the neighboring $\mathrm{C}-\mathrm{C}$ bonds, as shown in Fig. 3. Both structures are comparable in total-energy, but trans-cresol has a slightly lower energy (approximately $1 \mathrm{~kJ} / \mathrm{mol}$ with both conventional DFT and DFT-vdW) than cis-cresol, consistent with the experimental observation that trans-cresol is more energetically stable [4244]. We therefore chose trans-cresol for the following calculations whenever $o$-cresol was involved. The structural parameters of an isolated trans-cresol (hereafter $o$-cresol) are listed in Table 1.

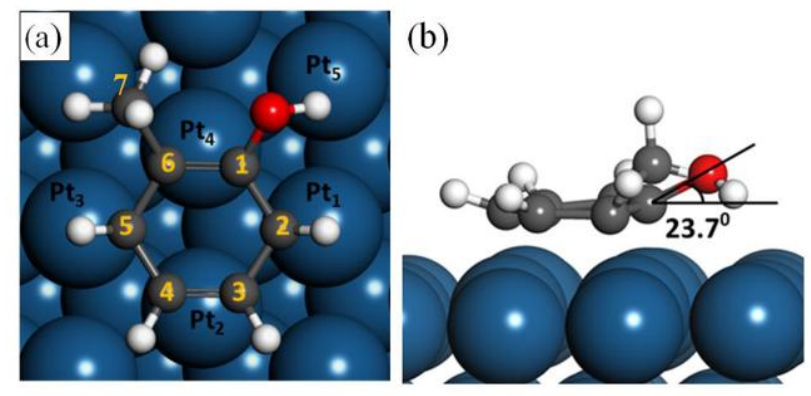

Figure 4. The optimized geometry of the most stable adsorption configuration of $o$-cresol on $\operatorname{Pt}(111)$ obtained from conventional DFT calculations: (a) top view, and (b) side view. Pt atoms are represented by largest spheres. $\mathrm{C}, \mathrm{O}$ and $\mathrm{H}$ atoms are represented by spheres in dark-grey, red, and light-grey, respectively. The angle of $25.3^{\circ}$ between the C6-C7 line and the $\mathrm{Pt}(111)$ surface is not shown as it is shaded by the hydroxyl group and part of the aromatic ring in the front. 
On the $\operatorname{Pt}(111)$ surface, $o$-cresol prefers a parallel configuration, in which the aromatic ring is almost parallel to the surface, as shown in Fig. 4. This result was obtained after the total energies of various parallel, tilted, and perpendicular configurations with different orientations were calculated. The total energy of the parallel configuration shown in Fig. 4 is lower than the tilted and perpendicular configurations with various orientations by $20-90 \mathrm{~kJ} / \mathrm{mol}$.

Similar parallel configurations were reported for phenol and $m$-cresol on the $\operatorname{Pt}(111)$ surface [12,27]. The center of the ring is located at a bridge site, and the closed-packed direction (corresponding to the line joining $\mathrm{Pt}_{2}$ and $\mathrm{Pt}_{4}$ in Fig. 4) and the main axis of its ring (the line connecting $\mathrm{C} 2$ and $\mathrm{C} 5$ ) are perpendicular each other. For an isolated $o$-cresol, the $\mathrm{C} 1-\mathrm{O}$ line (associated with the hydroxyl group) and the C6-C7 line (associated with the methyl group) essentially lie in the same plane of the aromatic ring. Upon adsorption, both hydroxyl and methyl groups are tilted up while the ring keeps almost parallel to $\mathrm{Pt}(111)$. The $\mathrm{C} 1-\mathrm{O}$ and $\mathrm{C} 6-\mathrm{C} 7$ lines are measured to be $23.7^{\circ}$ and $25.3^{\circ}$, respectively, away from the $\operatorname{Pt}(111)$ surface.

Detailed geometry parameters for the most stable bonding configuration determined by both conventional DFT and DFT-vdW are listed in Table 1. As shown in the table, the TS van der Waals corrections do not change the structure of $o$-cresol, and they have only very little effect on the distances of $o$-cresol with the Pt surface - only the H-Pt5 and O-Pt5 distances are slightly reduced when the vdW corrections are added to the calculations. Comparing the bonding configuration of $o$-cresol on $\operatorname{Pt}(111)$ with the geometry of isolated $o$-cresol, as shown in Table 1 , we find that all the C-C bond lengths in the ring are increased by $0.03-0.09 \AA$. The bond angles listed in Table 1 show some slight changes, increased or decreased by a degree less than $6^{\circ}$.

The binding energy for $o$-cresol on $\mathrm{Pt}(111)$ is $131 \mathrm{~kJ} / \mathrm{mol}$ (conventional DFT). If the van der Waals corrections are included, the binding energy is $257 \mathrm{~kJ} / \mathrm{mol}$, significantly greater than the 
Table 1. Bond lengths and bond angles of an isolated $o$-cresol ("Isolated" in the table) and the $o$-cresol molecule on the $\operatorname{Pt}(111)$ surface. Also shown are the distances between the atoms of $o$-cresol and the topmost platinum atoms. "On Pt (DFT)" and "On Pt (vdW)" refer to the values determined by conventional DFT and DFT-vdW calculations, respectively. Calculations were performed with a cutoff energy of $400 \mathrm{eV}$ and $2 \boldsymbol{k}$-points.

Bond length $(\AA)$

\begin{tabular}{lcccccccccc}
\hline & $\mathrm{C} 2 \mathrm{C} 3$ & $\mathrm{C} 3 \mathrm{C} 4$ & $\mathrm{C} 4 \mathrm{C} 5$ & $\mathrm{C} 5 \mathrm{C} 6$ & $\mathrm{C6C} 1$ & $\mathrm{C} 1 \mathrm{C} 2$ & $\mathrm{C} 6 \mathrm{C} 7$ & $\mathrm{C} 10$ & $\mathrm{OH}$ & $\mathrm{CH}$ \\
\hline Isolated & 1.40 & 1.39 & 1.40 & 1.40 & 1.41 & 1.40 & 1.50 & 1.38 & 0.97 & $1.09-1.10$ \\
On Pt (DFT) & 1.48 & 1.43 & 1.47 & 1.49 & 1.44 & 1.48 & 1.51 & 1.36 & 0.99 & $1.09-1.11$ \\
On Pt (vdW) & 1.48 & 1.43 & 1.47 & 1.49 & 1.45 & 1.48 & 1.51 & 1.36 & 0.99 & $1.09-1.11$ \\
\hline
\end{tabular}

Bond angle (degree)

\begin{tabular}{lcccccccccc}
\hline & C2C3C4 & C3C4C5 & C4C5C6 & C5C6C1 & C6C1C2 & C1C2C3 & OC1C6 & C7C6C1 & HOC1 \\
\hline Isolated & 119.8 & 119.3 & 122.2 & 117.4 & 121.1 & 120.2 & 117.0 & 120.7 & 108.8 \\
On Pt (DFT) & 122.5 & 122.5 & 116.0 & 120.3 & 123.7 & 114.2 & 115.2 & 118.0 & 109.5 \\
On Pt (vdW) & 122.6 & 122.5 & 116.0 & 120.3 & 123.6 & 114.2 & 115.4 & 118.2 & 109.3 \\
\hline
\end{tabular}

Distance to Pt (111) ( $\mathrm{A})$

\begin{tabular}{lcccccccc}
\hline & $\mathrm{C}-\mathrm{Pt}_{1}$ & $\mathrm{C} 3-\mathrm{Pt}_{2}$ & $\mathrm{C}-\mathrm{Pt}_{2}$ & $\mathrm{C} 5-\mathrm{Pt}_{3}$ & $\mathrm{C} 6-\mathrm{Pt}_{4}$ & $\mathrm{C} 1-\mathrm{Pt}_{4}$ & $\mathrm{H}-\mathrm{Pt}_{5}$ & $\mathrm{O}-\mathrm{Pt}_{5}$ \\
\hline On Pt (DFT) & 2.14 & 2.18 & 2.19 & 2.16 & 2.24 & 2.26 & 2.57 & 3.17 \\
On Pt (vdW) & 2.13 & 2.18 & 2.19 & 2.15 & 2.24 & 2.26 & 2.49 & 3.12 \\
\hline
\end{tabular}


value of conventional DFT. Previous DFT calculations with van der Waals corrections showed that the adsorption energies of phenol, guaiacol, and $m$-cresol on $\operatorname{Pt}(111)$ were $199 \mathrm{~kJ} / \mathrm{mol}, 219$ $\mathrm{kJ} / \mathrm{mol}$, and $176 \mathrm{~kJ} / \mathrm{mol}$, respectively [12,14,27]. We note that those calculations were performed with the use of smaller supercells (a 4-layer slab and a $4 \times 4$ surface unit cell) than the one that we use in this work (a 5-layer slab and a 5×5 surface unit cell). The experimental value for the adsorption energy of $o$-cresol on $\operatorname{Pt}(111)$ is not available. However, we calculated binding energies of other molecules on $\mathrm{Pt}(111)$ and we found that conventional DFT and DFT with vdW corrections (as implemented in the VASP code) underestimates and overestimates the binding energies, respectively, when compared to the experimental data. DFT with vdW corrections provides slightly better data than conventional DFT. For example, the experimental value for the binding energy of benzene on $\mathrm{Pt}(111), 203 \mathrm{~kJ} / \mathrm{mol}$ [45], falls between the DFT value of 147 $\mathrm{kJ} / \mathrm{mol}$ and the value of $240 \mathrm{~kJ} / \mathrm{mol}$ determined by DFT with vdW corrections. As the aromatic ring of $o$-cresol is similar to benzene, the exact binding energy of $o$-cresol on $\operatorname{Pt}(111)$ is likely to be in the region between $131 \mathrm{~kJ} / \mathrm{mol}$ (conventional DFT) and $257 \mathrm{~kJ} / \mathrm{mol}$ (DFT with the vdW correction).

The binding energies for a hydrogen atom on $\mathrm{Pt}(111)$ at different stable locations were also determined. We found that hydrogen located at an fcc site has the lowest total energy (with a binding energy of $267 \mathrm{~kJ} / \mathrm{mol}$ ). Therefore, while hydrogen diffuses on the surface at finite temperatures, it has a preference to be near the fcc sites.

Both hydrogen atoms and cresol adsorb strongly on the platinum surface, raising the questions of actual coverage and possible competition for sites. We found that a $5 \times 5$ surface unit can accommodate up to approximately three cresol molecules. We define the corresponding coverage as $1 \mathrm{ML}$. At $1 \mathrm{ML}$, all cresol molecules take the parallel configurations. Moreover, the 
space between the cresol molecules is large enough so that no strong repulsions between them are found. In our calculations for hydrogenation, we take the supercell model containing one cresol molecule per $5 \times 5$ surface cell. As the cresol molecules are essentially independent of each other, our calculations are valid for cresol courage up to $1 \mathrm{ML}$. Higher coverage than $1 \mathrm{ML}$ is unlikely because it will cause strong repulsion between the cresol molecules unless the cresol molecules assume perpendicular/tilted configurations, which have been shown to be energetically unfavorable. The experiments were carried out with platinum nanoparticles, which are characterized by faces, edges and corners. Cresol in its most favorable configuration resides on top of a flat ensemble of about seven platinum atoms, that is, it will be found on extended terraces present on the platinum nanoparticles. In contrast, hydrogen atoms are less demanding with respect to the site and are very mobile as indicated by the small diffusion barrier of approximately $10 \mathrm{~kJ} / \mathrm{mol}$. It is thus reasonable to assume coexistence of both reactants on the surface for elucidation of the hydrogenation mechanism.

We then performed calculations for the reaction energies and energy barriers for various transformations of $o$-cresol on the $\operatorname{Pt}(111)$ surface. Test calculations with several possible reactions showed that $\mathrm{vdW}$ corrections had insignificant effects on the reaction energies and energy barriers. For example, the reaction energies for dissociation of the hydrogen from the -OH group of cresol on Pt(111) determined with and without vdW corrections differ by less than $1 \mathrm{~kJ} / \mathrm{mol}$. In the following, we therefore report the calculations with conventional DFT only.

We considered the possibility of dissociation of $o$-cresol on $\operatorname{Pt}(111)$, that is, the hydrogen atom of the hydroxyl group migrates from $o$-cresol to the Pt surface (Fig. 5). During the migration process, hydrogen moves gradually to the surface with the final destination a nearby fcc site while the O-C bond length gradually decreases (and the hydrogen atom will then diffuse 
on the surface). The initial bond lengths of the $\mathrm{O}-\mathrm{H}$ and $\mathrm{O}-\mathrm{C}$ bonds are $0.99 \AA$ and $1.36 \AA$, respectively [Fig. 5(a)]. The transition state corresponds to the configuration in which the hydrogen atom is near an on-top site with a distance of $1.51 \AA$ to oxygen [Fig. 5(b)]. At the same time, the O-C bond length is reduced to $1.27 \AA$ (from the initial value of $1.36 \AA$ ). The final configuration involves dissociated hydrogen, which is at an fcc site on the surface with a distance of $3.56 \AA$ to the oxygen atom, and the O-C bond has now a bond length of $1.23 \AA$. The reaction is endothermic and the reaction energy is $28 \mathrm{~kJ} / \mathrm{mol}$. The energy barrier is $51 \mathrm{~kJ} / \mathrm{mol}$ (Fig. 6).

The possibility of migration of the hydrogen atom from the hydroxyl group to the nearby carbon atom (C2) in the aromatic ring was also investigated. Such a process, tautomerization [46], would result in the replacement of the $\mathrm{O}-\mathrm{H}$ bond by a new $\mathrm{C}-\mathrm{H}$ bond, as shown in Fig. 7. Our calculations show that a direct migration of hydrogen in $o$-cresol (one-step process of
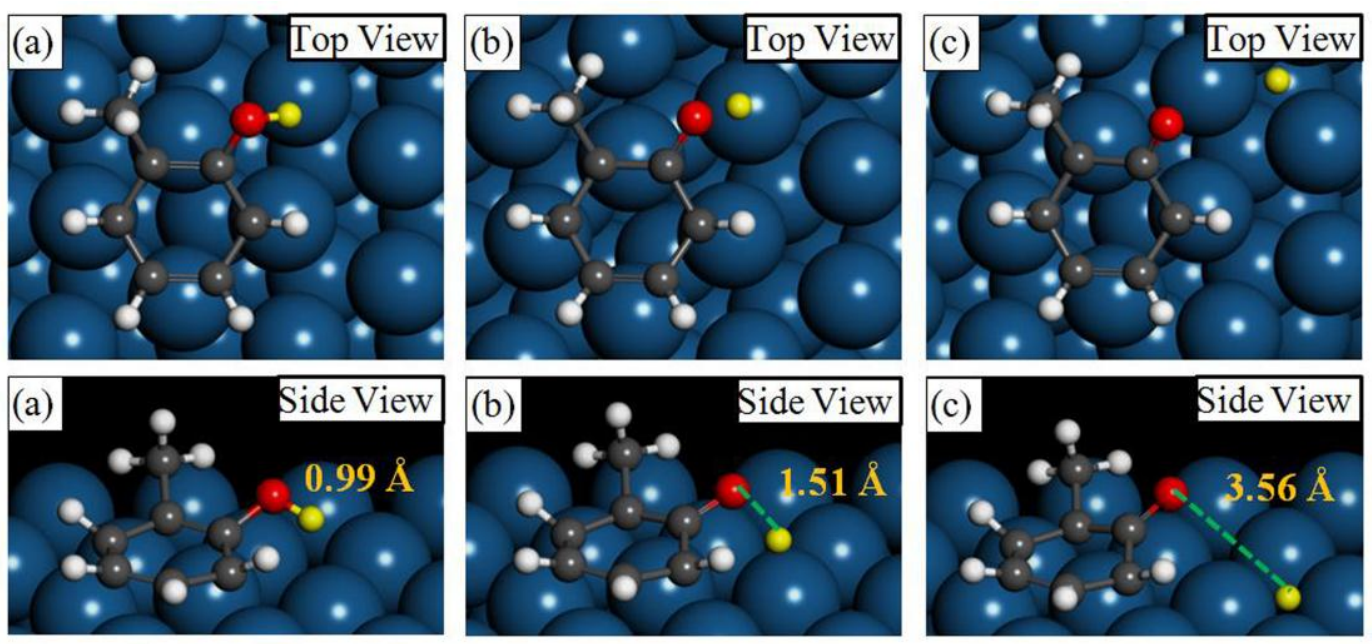

Figure 5. Schematics of migration of $\mathrm{H}$ of the hydroxyl group to the surface: (a) the initial configuration; (b) the transition state; and (c) the final configuration. The migrating hydrogen is highlighted in yellow. 


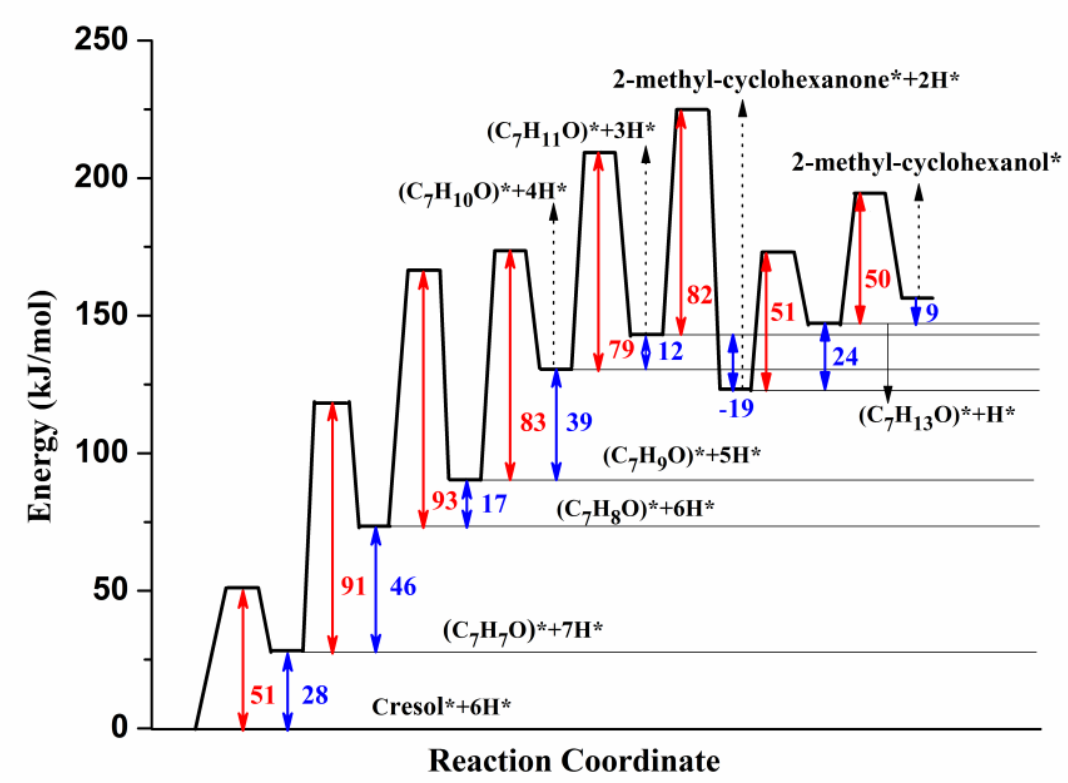

Figure 6. Diagram of reaction energies (in blue) and activation energies (in red) for reactions starting with hydrogen abstraction from the $-\mathrm{OH}$ group, followed by hydrogenation of the ring. The last two reactions are for hydrogenation of 2-methyl-cyclohexanone. The species on the surface are indicated by “*”.

tautomerization), as shown in Fig. 7, involves a reaction energy of $78 \mathrm{~kJ} / \mathrm{mol}$ and an energy barrier of $125 \mathrm{~kJ} / \mathrm{mol}$. The initial O-H bond has a bond length of $0.99 \AA$ [Fig. 7(a)]. This bond is broken in the transition state [Fig. 7(b)] as the O-H distance is $2.89 \AA$. At the same time, a new C-H bond is being formed as the bond length is $1.5 \AA$ in the transition state. Figure 7(c) shows that the final bond length of the newly formed $\mathrm{C}-\mathrm{H}$ bond is $1.12 \AA$. Recent work of tautomerization of $m$-cresol on $\mathrm{Pt}(111)$ and $\mathrm{Ru}(111)$ show similar values of the reaction energies and energy barriers [27]. Migration of the hydrogen to the C6 site of $o$-cresol involves even greater reaction energies $(116 \mathrm{~kJ} / \mathrm{mol})$ and barriers (which must be greater than or equal to the reaction energy when the reaction is endothermic). As a comparison, the corresponding energy barrier for tautomerization of $o$-cresol without any catalysis was calculated to be $255 \mathrm{~kJ} / \mathrm{mol}$. 
Therefore, $\operatorname{Pt}(111)$ significantly reduces the activation energy of tautomerization. However, the activation energy $(125 \mathrm{~kJ} / \mathrm{mol})$ for one-step tautomerization on Pt (Fig. 7) is still significantly greater than the corresponding value $(51 \mathrm{~kJ} / \mathrm{mol})$ for the migration of hydrogen to the surface (that is, cleavage of the $\mathrm{OH}$ bond of $o$-cresol), suggesting that one-step tautomerization is less likely to occur than the migration of hydrogen to the surface. The large difference between the two activation energies is due to the fact that one-step tautomerization involves not only dissociation of hydrogen from the -OH group but also hydrogenation of a carbon atom in the aromatic ring, resulting in a higher-energy transition state in which the hydrogen atom is located between the surface and the carbon atom (Fig. 7), whereas migration of hydrogen to the surface involves a lower-energy transition state in which bonding between the hydrogen atom and the surface is stronger (Fig. 5).
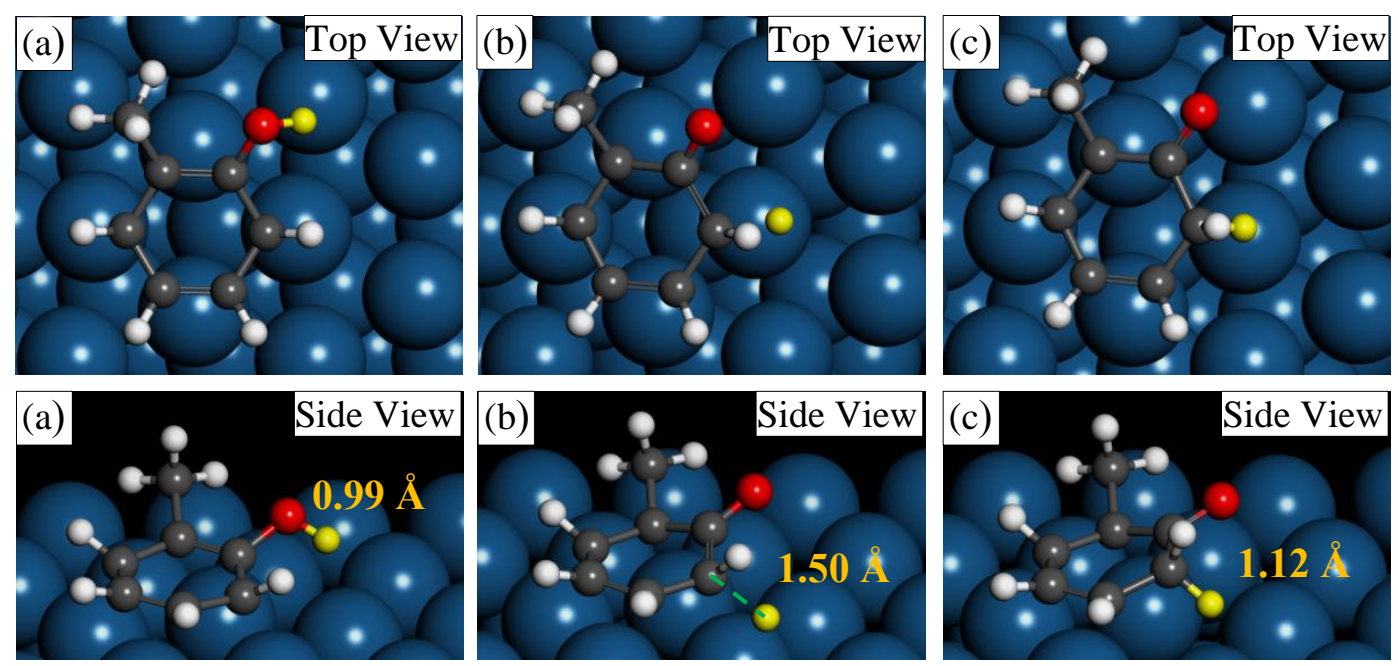

Figure 7. Schematics of one-step tautomerization on $\operatorname{Pt}(111)$ : (a) the initial configuration; (b) the transition state; (c) the final configuration. The migrating hydrogen is highlighted in yellow. 
With a two-step process, on the other hand, a tautomerization-like reaction could still occur with the condition that there are pre-existing hydrogen atoms nearby. After the hydrogen in the hydroxyl migrates to the surface, as shown in Fig. 5(c), a pre-existing hydrogen located near $o$ cresol can react with the carbon atoms in the ring, resulting in the configuration [Fig. 7(c)], which is also obtained after the one-step tautomerization. The second step, hydrogenation of $\mathrm{C} 2$ after removal of $\mathrm{H}$ from the $-\mathrm{OH}$ group, involves a reaction energy of $46 \mathrm{~kJ} / \mathrm{mol}$ and a barrier of $91 \mathrm{~kJ} / \mathrm{mol}$ (also see Fig. 6), with both values significantly smaller than those for the one-step tautomerization. We therefore conclude that the catalyst plays a critical role in dissociating the hydrogen from $o$-cresol and facilitates the following hydrogenation, the two-step process of the tautomerization-like reaction.

Previous work suggested that trace water could significantly promote tautomerization of enol-ketone in the gas phase and liquid phase without metal catalysis [47,48]. Therefore, while our study shows that $\operatorname{Pt}(111)$ plays an important role in reducing the barrier for cresol tautomerization, tautomerization could still occur without $\operatorname{Pt}(111)$ if trace water is involved. This implies that the importance of the metal for facilitating the tautomerization step could be dependent on the concentration of water in the cresol containing stream, which should be the focus of future studies.

We also studied the possible dissociation of the entire -OH group of $o$-cresol on $\operatorname{Pt}(111)$. However, the reaction energy is very high at $216 \mathrm{~kJ} / \mathrm{mol}$. As the energy barrier cannot be lower than the reaction energy, the barrier must be at least $216 \mathrm{~kJ} / \mathrm{mol}$. Such a high barrier suggests that the dissociation of the entire - $\mathrm{OH}$ group is unlikely to occur. 


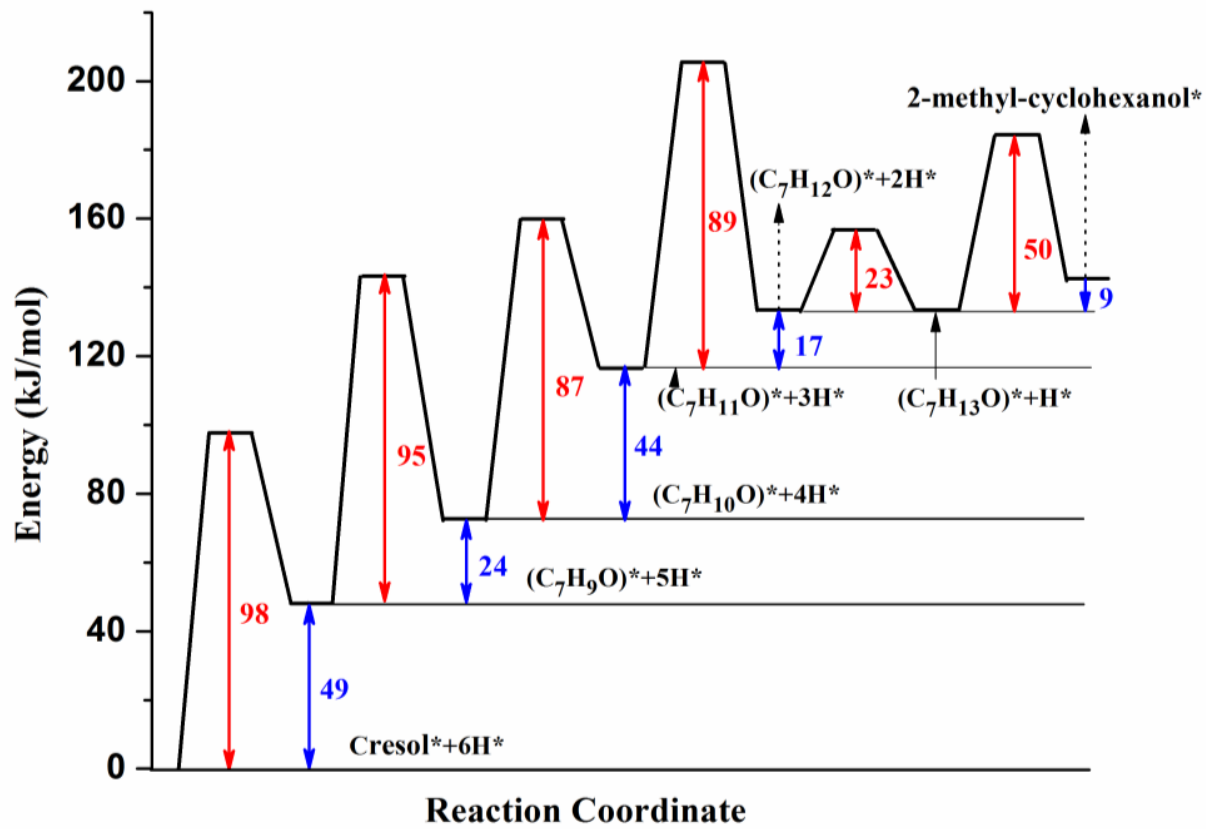

Figure 8. Diagram of reaction energies (in blue) and activation energies (in red), for reactions resulting in the formation of 2-methyl-cyclohexanol without hydrogen abstraction from the $-\mathrm{OH}$ group. The path starts with hydrogenation of the ring. The species on the surface are indicated by “*”.
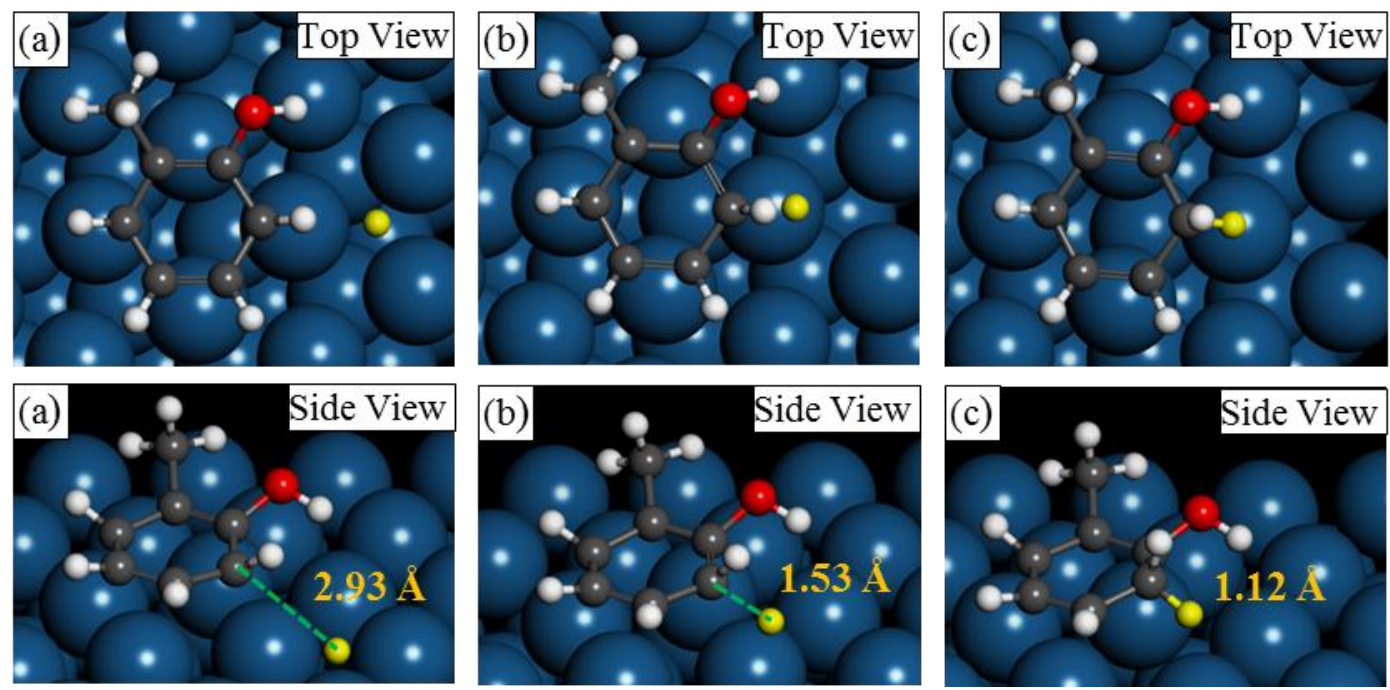

Figure 9. Schematics of addition of hydrogen atom to a carbon atom (C2) in the ring: (a) the initial configuration; (b) the transition state; and (c) the final configuration. The reacting hydrogen is highlighted in yellow. 
Assuming that $o$-cresol is adsorbed on $\operatorname{Pt}(111)$ and dissociation of the hydrogen in $o$-cresol has not happened yet, we considered the possibility of reactions of one hydrogen (hereafter the first hydrogen), which was located at a fcc site on Pt(111) before reaction, with a carbon atom $(\mathrm{C} 1, \mathrm{C} 2, \ldots$, and $\mathrm{C} 6)$ in the aromatic ring. The reaction of the first hydrogen with any of the carbon atoms in the ring was found to be endothermic, with a reaction energy of $49 \mathrm{~kJ} / \mathrm{mol}$ (with C2, also see Fig. 8), $37 \mathrm{~kJ} / \mathrm{mol}$ (with C3), $38 \mathrm{~kJ} / \mathrm{mol}$ (with C4), $42 \mathrm{~kJ} / \mathrm{mol}$ (with C5), $55 \mathrm{~kJ} / \mathrm{mol}$ (with C6), or $59 \mathrm{~kJ} / \mathrm{mol}$ (with C1). Similar values for the reaction energies of the ring hydrogenation of phenol on $\mathrm{Pt}(111)$ were reported previously [12].

As the local bonding structures of $\mathrm{C} 2$ and $\mathrm{C} 5$ are similar, and the same is true for $\mathrm{C} 3$ and $\mathrm{C} 4$, we calculated reaction pathways and the corresponding energy barriers of hydrogenation of $\mathrm{C} 2$ and $\mathrm{C} 4$. Figure 8 shows a typical hydrogenation when the first hydrogen and a carbon (C2) in the ring are involved. Initially, the first hydrogen is at an fcc site near C1 with a distance of $2.93 \AA$ [Fig. 9(a)]. During the reaction, hydrogen migrates toward C2 and gradually forms a C-H bond. Meanwhile, the hydrogen that was initially bonded to $\mathrm{C} 2$ is gradually titled up. The final structure is shown in Fig. 9(c), in which the first hydrogen is bonded with C2 with a bond length of $1.12 \AA$. The transition state corresponds to the configuration in which the first hydrogen is migrated to the location that is slightly off the on-top site [Fig. 9(b)], and distance between the first hydrogen and $\mathrm{C} 2$ is $1.53 \AA$. The energy barrier is $98 \mathrm{~kJ} / \mathrm{mol}$ (also see Fig. 8), significantly greater than the barrier for hydrogen abstraction from the -OH group of $o$-cresol $(51 \mathrm{~kJ} / \mathrm{mol})$. A similar pathway was found for hydrogenation of $\mathrm{C} 3$, but the energy barrier is considerably higher at $110 \mathrm{~kJ} / \mathrm{mol}$.

Assuming that hydrogen abstraction from the $-\mathrm{OH}$ group occurred already, the reaction energies and barriers for hydrogenation of the ring were determined. Such hydrogenation 
involves processes similar to that shown in Fig. 8 with an exception that the hydrogen of the -OH group is now removed. The resulting barriers are slightly reduced. The lowest barrier, still corresponding to hydrogenation of $\mathrm{C} 2$, is now $91 \mathrm{~kJ} / \mathrm{mol}$ (Fig. 6), $7 \mathrm{~kJ} / \mathrm{mol}$ smaller than the value of $98 \mathrm{~kJ} / \mathrm{mol}$ (Fig. 8) in the case that hydrogen abstraction did not occur. Therefore, dissociation of $o$-cresol slightly facilitates the following hydrogenation.

Next, assuming that one of the carbon atoms in the ring was already hydrogenated (with or without the hydrogen in the $-\mathrm{OH}$ group), the addition of hydrogen to another carbon was investigated. This hydrogenation step involved reduced energy barriers and reaction energies than the initial hydrogenation that involves the first hydrogen and a carbon in the ring. For example, Figure 10 shows the following hydrogenation (of C3) after the initial hydrogenation of
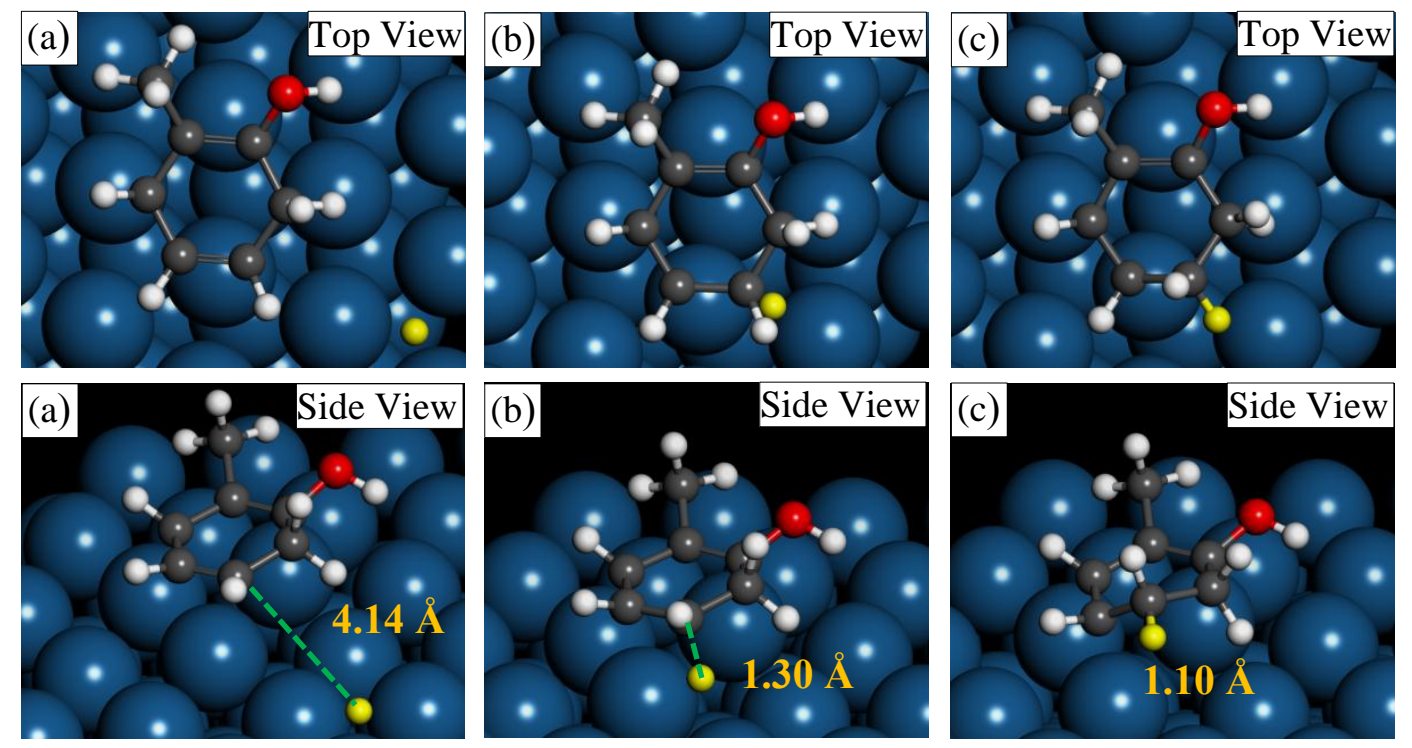

Figure 10. Schematics of following hydrogenation of a second carbon (C3) in the ring after the initial hydrogenation of the first carbon (C2): (a) the initial configuration; (b) the transition state; and (c) the final configuration. The reacting hydrogen is highlighted in yellow. 
C2. The barrier is significantly reduced to $95 \mathrm{~kJ} / \mathrm{mol}$ from approximately $110 \mathrm{~kJ} / \mathrm{mol}$ for the initial hydrogenation of $\mathrm{C} 3$ (also see Fig. 8). All of these results suggest that the initial hydrogenation of $o$-cresol always facilitates the following hydrogenation.

The successive hydrogenation of the ring carbons after dissociation of $\mathrm{H}$ in the $-\mathrm{OH}$ group can lead to the formation of the intermediate product, 2-methyl-cyclohexanone, as observed experimentally. A significant feature of the 2-methyl-cyclohexanone formation is that it prefers a tilted configuration on $\operatorname{Pt}(111)$, as shown in Fig. 11(b). On the other hand, all the species prior to the formation of 2-methyl-cyclohexanone show a parallel configuration, and the one immediately prior to the formation of 2-methyl-cyclohexanone is shown in Fig. 11(a). The tilted configuration of Fig. 11(b) has a lower total energy (by $24 \mathrm{~kJ} / \mathrm{mol}$ ) and hence a stronger binding (also by 24 $\mathrm{kJ} / \mathrm{mol}$ ) with the surface than the corresponding parallel configuration. The oxygen of 2-methylcyclohexanone points down towards the surface in the titled configuration, resulting in relatively stronger bonding with the surface than the parallel configuration. As a result, the reaction of the
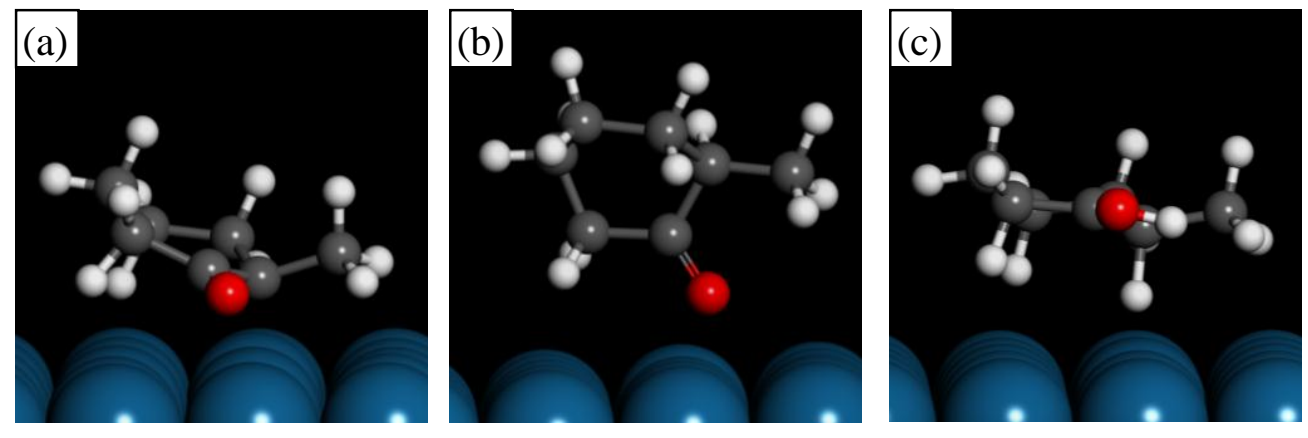

Figure 11. Schematics of the last step for the formation of the intermediate product: (a) the configuration immediately prior to the formation of 2-methyl-cyclohexanone; (b) the most stable bonding configuration of 2-methyl-cyclohexanone after it is formed on $\operatorname{Pt}(111)$. As a comparison, a parallel configuration of an intermediate product, which has weaker binding with the surface, is shown in (c). 


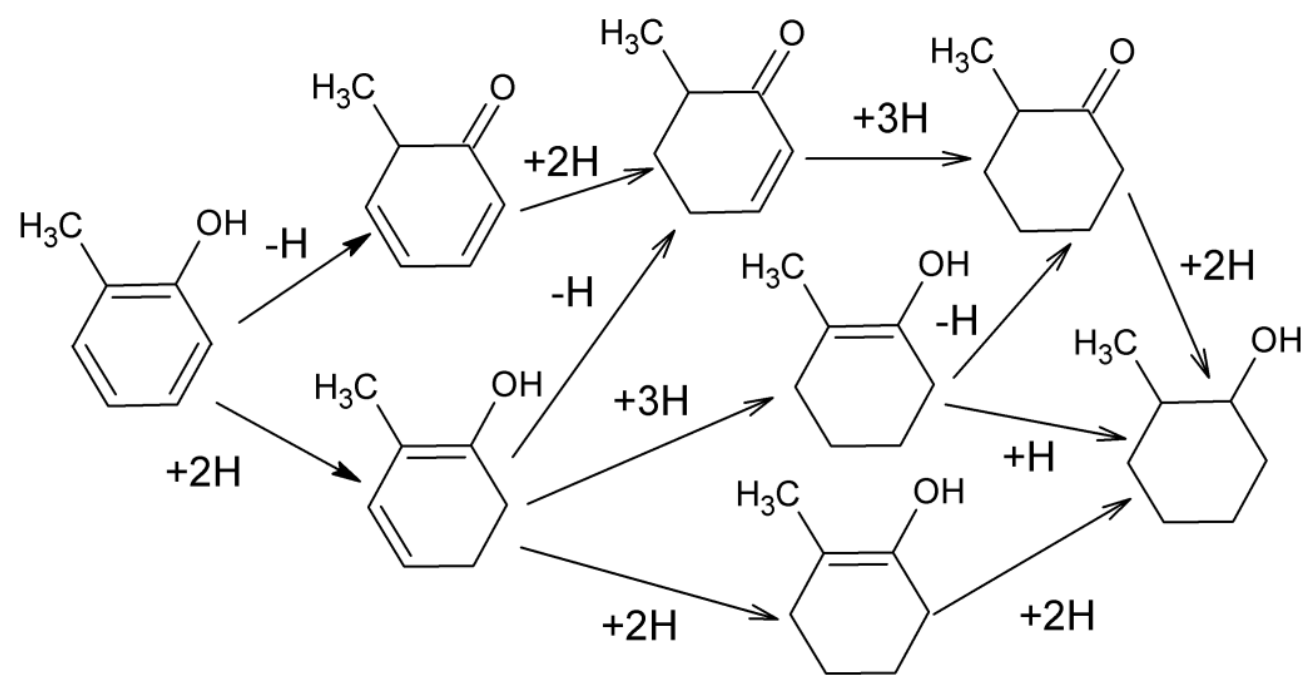

Scheme 1. Possible reaction paths that result in the formation of 2-methyl-cyclohexanone and 2-methyl-cyclohexanol.

last step for the formation of 2-methyl-cyclohexanone is exothermic with a reaction energy of $-19 \mathrm{~kJ} / \mathrm{mol}$. This is the only exothermic reaction during hydrogenation of the aromatic ring (also see Fig. 6).

As shown in Scheme 1, one possible reaction path is (the upper path in Scheme 1): the first step is hydrogen abstraction from the -OH group, followed by ring hydrogenation, which results in the formation of 2-methyl-cyclohexanone, and the last step involves hydrogenation of 2methyl-cyclohexanone (hydrogen migrates back to form the hydroxyl group and $\mathrm{C} 1$ is hydrogenated), that is, the formation of the final product, 2-methyl-cyclohexanol. The complete data for energetics of this path is shown in Fig. 6.

Meanwhile, as shown in Scheme 1 (lower paths), hydrogenation of the ring could occur without dissociation of $\mathrm{H}$ in the $-\mathrm{OH}$ group. There are two possibilities now. The first is that the ring is entirely hydrogenated while dissociation of $\mathrm{H}$ in the $-\mathrm{OH}$ group does not happen (the 
lowest path shown in Scheme 1). The diagram of energetics for the path is shown in Fig. 8. This path results in the formation of 2-methyl-cyclohexanol without the formation of 2-methylcyclohexanone. The other path involves hydrogen abstraction from the $-\mathrm{OH}$ group, during the process of partial hydrogenation of the aromatic ring, and the formation of the intermediate product 2-methyl-cyclohexanone, but the final product is the same (the middle paths shown in Scheme 1). While these results are obtained based on calculations for $o$-cresol, they also agree with the recent experimental work on catalytic hydrogenation of $m$-cresol at mild conditions [49]. Furthermore, as shown in Scheme 1, further hydrogenation of various surface intermediates may result in the formation of 2-methyl-cyclohexanol.

\section{Conclusions}

In conclusion, catalytic experiments show that hydrogenation of $o$-cresol on $\operatorname{Pt}(111)$ at relatively low reaction temperature results in the formation of the final product, 2-methylcyclohexanol, with 2-methyl-cyclohexanone as the intermediate product. Ab initio calculations provide a mechanism at the atomic-scale and interpretation of the experimental observations. Dissociation of $\mathrm{H}$ in the $-\mathrm{OH}$ group involves a low barrier. Such dissociation promotes hydrogenation of the aromatic ring, which results in the formation of the intermediate product. Further hydrogenation of 2-methyl-cyclohexanone results in the formation of the final product, 2-methyl-cyclohexanol. Hydrogenation of $o$-cresol without dissociation of $\mathrm{H}$ in the $-\mathrm{OH}$ group is also possible though the barrier is slightly higher. Such process generates the final product directly. 


\section{Acknowledgements}

This work was supported by the United States Department of Energy under Grant No. DESC0004600. The research used supercomputer resources of the Extreme Science and Engineering Discovery Environment (XSEDE) and the Texas Advanced Computing Center (TACC) at The University of Texas at Austin, of the National Energy Research Scientific

Computing Center, which is supported by the Office of Science of the U.S. Department of Energy under Contract No. DE-AC02-05CH11231, and of the Tandy Supercomputing Center (TSC) at Tulsa, Oklahoma.

\section{Reference:}

[1] D.C. Elliott, Historical developments in hydroprocessing bio-oils, Energy Fuels 21 (2007) 1792-1815.

[2] D. Mohan, C.U. Pittman Jr., P.H. Steele, Pyrolysis of wood/biomass for bio-oil: A critical review, Energy Fuels 20 (2006) 848-889.

[3] G. Huber, S. Iborra, A. Corma, Synthesis of transportation fuels from biomass: Chemistry, catalysts, and engineering, Chem. Rev. 106 (2006) 4044-4098.

[4] A. Oasmaa, S. Czernik, Fuel oil quality of biomass pyrolysis oils-state of the art for the end users, Energy Fuels 13 (1999) 914-921. 
[5] C. Liu, H. Wang, A.M. Karim, J. Sun, Y. Wang, Advances in catalytic pyrolysis of lignocellulosic biomass, Chem. Soc. Rev. 43 (2014) 7594-7623.

[6] P. McKendry, Energy production from biomass (Part 2): Conversion technologies, Bioresour. Technol. 83 (2002) 47-54.

[7] D.C. Elliott, Biofuel from fast pyrolysis and catalytic hydrodeoxygenation, Curr. Opin. Chem. Eng. 9 (2015) 59-65.

[8] X. Zhu, L.L. Lobban, R.G. Mallinson, D.E. Resasco, Bifunctional transalkylation and hydrodeoxygenation of anisole over a Pt/HBeta catalyst, J. Catal. 281 (2011) 21-29.

[9] M. Saidi, F. Samimi, D. Karimipourfard, T. Nimmanwudipong, B.C. Gates, M.R. Rahimpour, Upgrading of lignin-derived bio-oils by catalytic hydrodeoxygenation, Energy Environ. Sci. 7 (2014) 103-129.

[10] C.A. Mullen, A.A. Boateng, Chemical composition of bio-oils produced by fast pyrolysis of two energy crops, Energy Fuels 22 (2008) 2104-2109.

[11] M. Honkela, J. Björk, M. Persson, Computational study of the adsorption and dissociation of phenol on Pt and Rh surfaces, Phys. Chem. Chem. Phys. 14 (2012) 5849-5854.

[12] G. Li, J. Han, H. Wang, X. Zhu, Q. Ge, Role of dissociation of phenol in its selective hydrogenation on Pt (111) and Pd (111), ACS Catal. 5 (2015) 2009-2016.

[13] C. Chiu, A. Genest, A. Borgna, N. Rösch, Hydrodeoxygenation of guaiacol over Ru(0001): A DFT study, ACS Catal. 4 (2014) 4178-4188.

[14] J. Lu, S. Behtash, O. Mamun, A. Heyden, Theoretical investigation of the reaction mechanism of the guaiacol hydrogenation over a Pt(111) catalyst, ACS Catal. 5 (2015) 24232435 . 
[15] K. Lee, G.H. Gu, C.A. Mullen, A.A. Boateng, D.G. Vlachos, Guaiacol hydrodeoxygenation mechanism on $\operatorname{Pt}(111)$ : Insights from density functional theory and linear free energy relations, ChemSusChem 8 (2015) 315-322.

[16] S. Boonyansuwat, T. Omotoso, D.E. Resasco, S.P. Crossley, Conversion of guaiacol over supported Ru catalysts, Catal. Lett. 143 (2013) 783-791.

[17] T. Omotoso, S. Boonyansuwat, S.P. Crossley, Understanding the role of $\mathrm{TiO}_{2}$ crystal structure on the enhanced activity and stability of $\mathrm{Ru} / \mathrm{TiO}_{2}$ catalysts for the conversion of ligninderived oxygenates, Green Chem.16 (2014) 645-652.

[18] Y. Takagi, S. Nishimura, K. Taya, K. Hirota, The hydrogenation of $o-, m-$, and $p$-cresols with a rhodium catalyst, J. Catal. 8 (1967) 100-104.

[19] H. Hichri, A. Accary, J. Andrieu, Kinetics and slurry-type reactor modelling during catalytic hydrogenation of $o$-cresol on $\mathrm{Ni}_{/} \mathrm{SiO}_{2}$, Chem. Eng. Process 30 (1991) 133-140.

[20] E. Shin, M.A. Keane, Catalytic hydrogen treatment of aromatic alcohols, J. Catal. 173 (1998) 450-459.

[21] E.O. Odebunmi, D.F. Ollis, Catalytic hydrodeoxygenation .1. conversions of ortho-cresols, para-cresols, and meta-cresols, J. Catal. 80 (1983) 56-64.

[22] R. Wandas, J. Surygala, E. Sliwka, Conversion of cresols and naphthalene in the hydroprocessing of 3-component model mixtures simulating fast pyrolysis tars, Fuel 75 (1996) 687-694.

[23] L. Nie, P.M. de Sluza, F.B. Noronha, W. An, T. Sooknoi, D.E. Resasco, Selective conversion of $m$-cresol to toluene over bimetallic Ni-Fe catalysts, J. Mol. Catal. A: Chem. 388389 (2014) 47-55. 
[24] M.S. Zanuttini, B.O. Dalla Costa, C.A. Querini, M.A. Peralta, Hydrodeoxygenation of $m$ cresol with Pt supported over mild acid materials, Appl. Catal. A: Gen. 482 (2014) 352-361. [25] J. Horáček, G. Štávová, V. Kelbichová, D. Kubička, Zeolite-Beta-supported platinum catalysts for hydrogenation/hydrodeoxygenation of pyrolysis oil model compounds, Catal. Today 204 (2013) 38-45.

[26] R.C. Nelson, B. Baek, P. Ruiz, B. Goundie, A. Brooks, M.C. Wheeler, B.G. Frederick, L.C. Grabow, R.N. Austin, Experimental and theoretical insights into the hydrogen-efficient direct hydrodeoxygenation mechanism of phenol over $\mathrm{Ru} / \mathrm{TiO}_{2}$, ACS Catal. 5 (2015) 6509-6523. [27] Q. Tan, G. Wang, L. Nie, A. Dinse, C. Buda, J. Shabaker, D.E. Resasco, Different product distributions and mechanistic aspects of the hydrodeoxygenation of $m$-Cresol over Platinum and Ruthenium catalysts, ACS Catal.5 (2015) 6271-6283.

[28] P.E. Blöchl, Projector augmented-wave method, Phys. Rev. B 50 (1994) 17953-17979.

[29] G. Kresse, J. Furthmüller, Efficient iterative schemes for ab initio total-energy calculations using a plane-wave basis set, Phys. Rev. B 54 (1996) 11169-11186.

[30] G. Kresse, D. Joubert, From ultrasoft pseudopotentials to the projector augmented-wave method, Phys. Rev. B 59 (1999) 1758-75.

[31] R. Car, M. Parrinello, Unified approach for molecular dynamics and density-functional theory, Phys. Rev. Lett. 55 (1985) 2471-2474.

[32] J.P. Perdew, K. Burke, M. Ernzerhof, Generalized gradient approximation made simple, Phys. Rev. Lett. 77 (1996) 3865-3868.

[33] M.C. Payne, M.P. Teter, D.C. Allan, T.A. Arias, J.D. Joannopoulos, Iterative minimization techniques for ab initio total-energy calculations: molecular dynamics and conjugate gradients, Rev. Mod. Phys. 64 (1992) 1045-1097. 
[34] S.-Y. Liu, S. Liu, D. Li, T.M. Drwenski, W. Xue, H. Dang, S. Wang, Oxidation mechanism of the intermetallic compound $\mathrm{Ti}_{3} \mathrm{Al}$ from ab initio thermodynamics, Phys. Chem. Chem. Phys. 14 (2012) 11160-11166.

[35] S. Wang, H.L. Dang, W.H. Xue, D. Shields, X. Liu, F.C. Jentoft, D.E. Resasco, Ab initio molecular dynamics simulations of furfural at the liquid-solid interface, Int. J. Math. Comput. Phys. Nucl. Sci. Eng. 7 (2013) 102-105.

[36] S.-Y. Liu, J.-X. Shang, F.-H. Wang, S. Liu, Y. Zhang, D. Li, D. Shields, W. Xue, Y. Liu, H. Dang, S. Wang, Oxidation of the two-phase $\mathrm{Nb} / \mathrm{Nb}_{5} \mathrm{Si}_{3}$ composite: The role of energetics, thermodynamics, segregation, and interfaces, J. Chem. Phys. 138 (2013) 014708.

[37] S.-Y. Liu, Y. Liu, D.-J. Li, S. Wang, J. Gao, Y. Shen, Ab initio atomistic thermodynamics study on the oxidation mechanism of binary and ternary alloy surfaces, J. Chem. Phys. 142 (2015) 064705.

[38] A. Tkatchenko, M. Scheffler, Accurate molecular van der Waals interactions from groundstate electron density and free-atom reference data, Phys. Rev. Lett. 102 (2009) 073005.

[39] G. Henkelman, B. P. Uberuaga, H. Jónsson, A climbing image nudged elastic band method for finding saddle points and minimum energy paths, J. Chem. Phys. 113 (2000) 9901-9904. [40] G. Henkelman, H. Jónsson, Improved tangent estimate in the nudged elastic band method for finding minimum energy paths and saddle points, J. Chem. Phys. 113 (2000) 9978-9985. [41] C. Kittel, Introduction to Solid State Physics, seventh ed., John Wiley \& Sons, Inc., New York, 1996

[42] T. Aota, T. Ebata, M. Ito, Rotational isomers and internal rotation of the methyl group in S0, S1 and ion of $o$-cresol, J. Phys. Chem. 93 (1989) 3519-3522. 
[43] A. Fujii, E. Fujimaki, T. Ebata, N. Mikami, A new type of intramolecular hydrogen bonding: hydroxyl-methyl interactions in the o-cresol cation, J. Am. Chem. Soc. 120 (1998) 13256-13257.

[44] P. Wu, S. Guo, S. Li, F. Tao, Theoretical study of mechanism and kinetics for OH-initiated oxidation of $o$-cresol in the troposphereOriginal, Comp. Theo. Chem. 971 (2011) 51-57.

[45] H. Ihm, H.M. Ajo, J.M. Gottfried, P. Bera, C.T. Campbell, Calorimetric measurement of the heat of adsorption of benzene on $\operatorname{Pt}(111)$, J. Phys. Chem. B 108 (2004) 14627-14633.

[46] Y. Yoon, R. Rousseau, R.S. Weber, D. Mei, J.A. Lercher, First-principles study of phenol hydrogenation on Pt and Ni catalysts in aqueous phase, J. Am. Chem. Soc. 136 (2014) 1028710298.

[47] T. Ishida, F. Hirata, S. Kato, Thermodynamic analysis of the solvent effect on tautomerization of acetylacetone: An ab initio approach, J. Chem. Phys. 110 (1999) 3938-3945. [48] G. Alagona, C. Ghio, Keto-enol tautomerism in linear and cyclic $\beta$-diketones: A DFT study in vacuo and in solution, Int. J. Quantum Chem. 108 (2008) 1840-1855.

[49] C. Chen, G. Chen, F. Yang, H. Wang, J. Han, Q. Ge, X. Zhu, Vapor phase hydrodeoxygenation and hydrogenation of $m$-cresol on silica supported Ni, Pd and Pt catalysts, Chem. Eng. Sci. 135 (2015) 145-154. 
Graphical abstract

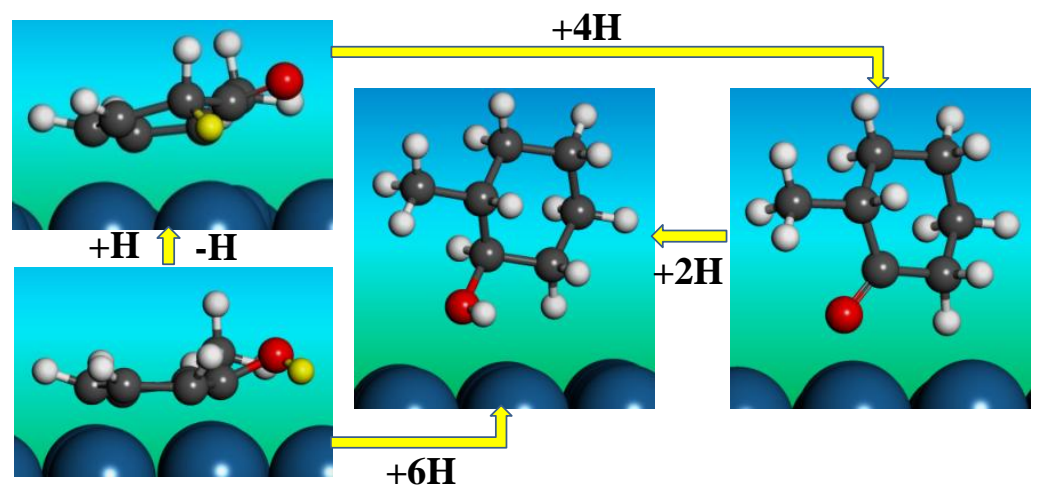

